\title{
Arte, tempo, fim do mundo e salvação (a partir da filosofia) ${ }^{1}$
}

\author{
Sofia Miguens \\ Universidade do Porto - IF
}

Resumo: Neste artigo considero o problema das relações da arte com o tempo partindo de uma definição anti-essencialista de arte que é aceite hoje por muitos autores em estética, a definição intencional-histórica de Jerry Levinson. Segundo essa definição é arte aquilo que é proposto intencionalmente por um artista como arte contra um pano de fundo da história da arte, independentemente das características intrínsecas dos objetos. Para mostrar alguns problemas do apelo à história que é assim feito quando se trata de pensarmos naquilo que conta como arte exploro, apoiada no filósofo israelita Eli Friedlander, os pressupostos filosóficos da ideia de Walter Benjamin segundo a qual a arte é a única salvação (e a única revolução) possível e que dizem respeito, especificamente, à linguagem.

Palavras-chave: arte e tempo, definições anti-essencialistas de arte, Benjamin, linguagem

\begin{abstract}
In this article I consider the problem of how art and time relate starting from a currently widely accepted anti-essentialist definition of art, Jerry Levinson's intentionalhistorical definition. According to such definition, art is what is intentionally proposed as art by an artist against the background of the history of art, independently of the intrinsic properties of objects. The problem, though, is what we mean by 'history' here. In order to highlight some of the assumptions of such approach (namely where these concern language) I explore the background of Walter Benjamin's idea that art is the sole salvation and revolution possible. I do it by appealing to Israeli philosopher Eli Friedlander's interpretation of Benjamin's work.
\end{abstract}

Keywords: art and time, anti-essentialist definitions of art, Benjamin, language 
Os Seminários do Fim do Mundo dão o nome perfeito ao nosso tempo, ou pelo menos à forma como o sentimos. Falar de salvação, por outro lado, traz consigo alguma forma de pensar sobre o mundo, o tempo e a história. É essa forma de pensar que determina qual o mundo que vemos acabar ou não acabar e o que entendemos por 'ser salvo' (neste mundo, noutro mundo, em termos políticos, religiosos, ecológicos ou outros). No que se segue exploro os temas do fim do mundo e da salvação em torno da arte e a partir da filosofia.

\section{Nós próprios, hoje, perante as artes.}

Quando começamos as nossas incursões pelas artes, seja pela literatura, pelas artes plásticas, pela música, pelo cinema, ou por outras artes, é possível que a certo ponto paremos e perguntemos a nós próprios: mas o que é isto, a arte? Porque é que humanos se envolvem em atividades tais? Porque é que este amontoado de tijolos e lixo e fotografias mais ou menos pessoais à minha frente, num museu, no meio de uma sala, há-de ser arte (Pedro Cabrita Reis 2020: A Roving Gaze, Serralves)? Porque é que estas barras metálicas brancas, colocadas em frente ao mar, em Leça da Palmeira, e que tanto exaltaram a certo ponto os lecenses, hão-de de ser arte (Pedro Cabrita Reis 2019: A Linha do Mar)? Porque é que um lince gigantesco, divertido e colorido, feito de lixo e instalado no Parque das Nações, há-de ser arte (Bordalo II 2019: Lince)? Porque é que uma mulher pesada, nua, com um quadro de Mondrian pintado na pele, há-de ser arte (Jakob Lena Knebl 20I2: performance-instalação-fotografia, Piet I-III)? Poderíamos neste ponto pegar no conceito de mundo da arte do filósofo e crítico de arte Arthur Danto e dizer que é arte aquilo que o mundo da arte declara que conta como arte, institui como arte. Isto parece no entanto significar que é arte aquilo que os cognoscenti declaram que conta como arte, o que parece arbitrário e injustificadamente elitista. ${ }^{2}$ Talvez a arte não queira mais do que imitar a realidade e para isso não precisa do reconhecimento de ninguém. Esta ideia simples e antiga é no entanto particularmente polémica. Por exemplo Platão não gostava de todo da ideia de imitação, a que chamava mimese: no livro X da República, a 'arte' como mimese é comparada com um espelho, um espelho com que alguém andasse por todo o lado, trazendo à existência objetos aparentes, duplos redundantes, objetos desprovidos de existência real e que não nos trazem qualquer benefício cognitivo (República 596e). Mas, na verdade, será que a arte quer sempre imitar? Consideremos por exemplo a arte feita com palavras e as estranhas coisas que fazemos com palavras, por exemplo em poesia. Pomos palavras comuns fora do lugar, transpomo-las, repetimo-las noutros contextos: será que as palavras “Hurry up please it's time” em The Waste Land de T.S. Eliot são imitadas 
das palavras de uma mulher real num pub real? Será que as palavras finais do poema, shanti shanti shanti, são imitadas dos Upanishads?

Quando os filósofos discutem hoje estas questões, nomeadamente em estética, indo atrás de definições de arte, discutindo se a arte tem uma essência ou não, as definições anti-essencialistas têm muita adesão. Elas opõem-se aos tradicionais essencialismos, que evocam características como a imitação ou representação, ou a expressão de sentimentos ou a forma significante como sendo definidoras da arte. ${ }^{3}$ Pura e simplesmente não parece haver características intrínsecas aos objetos que tornem um objeto um objeto de arte. Num tempo como o nosso aparentemente tudo pode ser arte. Mais de cem anos depois de Duchamp, mais de sessenta depois de Wahrol, após vagas e vagas de modernismos em artes diversas, não parece ser de todo uma boa ideia ligar o ser arte com características intrínsecas de objetos. Não parece haver marcas específicas que distingam a arte de outras coisas do mundo: os objetos, situações e eventos que fazem acontecer arte podem ser perfeitamente banais. Um problema assalta-nos no entanto quando perdemos a presunção de sermos essencialistas. Há práticas a que costumávamos chamar 'literatura', 'música', 'pintura', ‘teatro', ‘arquitectura', e subitamente parece que perdemos os automatismos que nos permitiriam simplesmente continuá-las. Mas a verdade é que nós continuamos essas práticas, queremos continuá-las e conseguimos fazê-lo, por vezes com sucesso, por vezes sem sucesso. Como pode isto ser? Afinal, que qualquer coisa possa ser arte não significa que tudo seja arte. Apesar de tudo, parece que pelo menos algumas características têm de estar presentes para que objetos, eventos, gestos ou situações aconteçam como arte. Um lance teórico aceite por muitos neste ponto é declarar que alguma coisa é arte quando é intencionalmente colocada sobre o pano de fundo daquilo que foi arte, daquilo que foi tratado como arte, evocando o facto bruto de alguns objetos e situações no passado, e não todos, terem sido tomados e tratados como arte. Evita-se desta forma o elitismo e o sociologismo da definição de Danto que evoquei acima: vermos alguma coisa como arte agora depende não tanto de alguém estar aí para certificar, garantir ou empossar socialmente um determinado objeto, gesto ou acontecimento como arte, mas do facto bruto de arte ter realmente acontecido no passado sob determinadas formas. É isto que pretende a chamada definição intencional-histórica de Jerry Levinson (2020). Segundo Levinson, é arte aquilo que é intencionalmente posicionado pelo artista sobre um pano de fundo de história de arte - se não fosse esse pano de fundo da história da arte, que faz um gesto, um objeto, um conjunto de sons ressoar de uma certa maneira, então esse gesto, objeto, conjunto de sons seriam banais, coisas e acontecimentos mundanos por entre coisas e acontecimentos mundanos. Parece então que o tempo presente não está sozinho e que precisamos da história, nomeadamente da história da arte para ver objetos ou acontecimentos de arte como arte. Mas o que é história da arte e como chegamos a fechá-la em livros, a fechar as listas das coisas que contamos como 
obras a considerar, como a tradição que é preciso conhecer, como 'cânone'? Quando chamamos a algumas coisas e não a outras 'pintura', 'literatura', 'escultura', o que estamos a fazer? A verdade é que não é necessariamente mais simples evocar a história da arte para podermos dizer o que é arte do que falar no mundo da arte, como faz Danto. Ao evocar a história da arte somos nomeadamente obrigados a enfrentar a questão das relações da arte com o tempo - e é para isso que vou recorrer a Walter Benjamin. Benjamin foi uma figura bizarra, marginal e muito importante no pensamento sobre arte e história, e alguém que de facto aproximou arte e salvação. Na verdade Benjamin viu a arte como a única salvação (e a única revolução) possível neste nosso mundo humano. Se alguma vez a salvação vier, ela virá da arte, e não por exemplo da ação política sobre o mundo, ou do conhecimento. Este salto para fora do mundo material e político pode parecer ter algo de religioso. No entanto, sendo judeu, Benjamin não era propriamente religioso, da mesma forma que sendo marxista não era propriamente um marxista ortodoxo. Desde logo não aceitava a visão dialética da história e da revolução característica do marxismo - pensava que esta assentava sobre uma conceção errada de tempo, um tempo como contentor vazio, onde existiriam factos enfileirados, como que pendurados numa corda, inertes. E Benjamin pensou que pensar bem sobre tempo é absolutamente decisivo para pensar sobre arte. Como vê então Benjamin o tempo e a história e a arte que neles acontece? Sabemos que é um marxista não ortodoxo, sabemos que acredita na revolução (pela arte), sabemos que proclamou que “A catástrofe é a condição permanente do presente”. Mas o que quer tudo isto dizer? O que se segue são algumas notas sobre Benjamin, tempo e arte e salvação, em parte motivadas pelo livro Walter Benjamin - A philosophical portrait (2012) do filósofo israelita Eli Friedlander. Espero que sirvam para esclarecer de que forma pode Benjamin ainda hoje iluminar a discussão filosófica sobre o que a arte é e o que a arte faz, um contexto em que se digladiam ideias alternativas de autores tão diversos entre si como o filósofo analítico Jerry Levinson ou essa figura magna da filosofia continental que é Martin Heidegger, de quem me servirei para alguns contrastes.

\section{0 comum, a história e a arte.}

Consideremos o mundo à nossa volta, o que está aí, o comum. Nem tudo é óbvio no que é manifesto, no que se vê à primeira vista. É precisamente esse o caso da historicidade daquilo que nos rodeia. Nós herdamos o passado. Naquilo que nos rodeia, na vida material, nas artes, na filosofia, estamos perante a presença do passado no presente. No entanto isso não é como nada para nós. A historicidade daquilo que nos rodeia é algo em que estamos imersos, algo de que quase certamente não nos apercebemos. 0 que é por exemplo para mim tudo à minha volta neste momento ser de uma dada época, os écrans de computador, os livros, os móveis, os prédios que vejo pela janela? Não é como nada para mim, o que há aí à minha volta aparece-me como simplesmente natural. Não seria assim se este mesmo contexto material fosse transposto no tempo. Ima- 
gine-se que teríamos estes mesmos écrans, livros, móveis, os prédios que vejo pela janela, e que teriam passado duzentos anos. Passados duzentos anos a naturalidade e o óbvio desapareceriam e a estranheza apareceria. Ou façamos a experiência inversa. Imaginemos que estamos no mumok, em Viena, numa exposição imaginária sobre a Secessão, os Wiener Werkstätte, os trabalhos do arquiteto Adolf Loos, uma exposição em torno do que se passava na transição de século entre o século dezanove e o século vinte, e até cerca dos anos trinta, em torno de objetos comuns de mobiliário e em torno de arquitetura. Andamos pela exposição e aprendemos factos sobre as discussões explosivas e apaixonadas, na Viena do passado relativamente recente, sobre o design dos objetos comuns, sobre arquitetura e a sua função, lemos alguns extratos de Ornamento e Crime de $\operatorname{Loos}^{4}$ na parede, lemos acerca do horror dos vienenses perante a fachada clean da Looshaus em Michaelerplatz. Compreendemos tudo isso, e no entanto o efeito de novidade e disrupção, o coração dessas discussões e disputas, desapareceu. Tudo isso se tornou história para nós. ${ }^{5}$ Nós somos já os herdeiros, estamos depois, vimos depois. 0 que significa no entanto algo tornar-se história? Como estamos nós em relação com tudo isso que já não é presente mas a que de alguma forma temos ainda acesso? Como é que, apesar da voracidade do tempo, apesar do desaparecimento das coisas, algo se conserva daquilo que passa no que está perante nós? Quando alguém faz apelo à história da arte - por exemplo os filósofos analíticos discutindo definições de arte - estas questões são inevitáveis. Afirmar, como o faz por exemplo Levinson, que alguma coisa é arte quando é intencionalmente posicionada pelo artista sobre o pano de fundo da história da arte, quando é para ser tratada da mesma forma que obras de arte anteriormente existentes foram tratadas, estamos a assumir que há coisas que têm sido tratadas como arte, que nós sabemos quais são essas coisas, que há uma história dessas coisas, que algo delas chega até nós, por exemplo sob a forma de fotografias num livro de história de arte. Mas que 'história' é essa? Por que são essas, exatamente, as coisas que estão aí, num livro de história de arte, e não outras? Como sabemos nós que as coisas que foram tratadas como arte foram exatamente essas? ${ }^{6} \mathrm{~A}$ intenção do próprio Levinson, ao defender que algo é arte ‘à luz daquilo que a arte tem sido', é erguer a concretude daquilo que a arte tem sido contra uma definição institucional de arte, com o seu apelo ao mundo da arte e ao que este reconhece como artes. $\mathrm{O}$ apelo ao que a arte tem sido - à história da arte concreta, digamos, àquilo que realmente foi, àquilo que realmente existiu - pretende superar a vagueza e nebulosidade do conceito demasiadamente sociológico de 'mundo da arte', lido como sanção e investidura pelo establishment presente. No entanto, apelar à história da arte e ao que a arte tem sido não é necessariamente mais simples do que evocar o mundo da arte. Por um lado, porque coloca inevitavelmente todas as questões acerca de história e tempo que explicitei acima, questões acerca daquilo que fica naquilo que passa. Por outro lado, porque não é sequer simples, desde logo, saber o que pode significar 'a história da arte' no nosso tempo, o tempo da arte glo- 
bal e de um mundo da arte internacional, que faz confluir comunidades e tradições díspares e incomunicantes durante séculos, situação que é hoje de resto assumida e incorporada por tantos artistas eles próprios no seu trabalho. ${ }^{7}$ Haverá, nestas circunstâncias, realmente uma história da arte una e unificada? A história de arte de quem? Dos europeus e americanos e da sua cultura erudita, a história da sucessão das vanguardas em artes diversas? Por que seria assim? Um problema, a partir da filosofia, com o facto de ter deixado de ser pacífica para nós a referência a uma história da arte única, marcada por histórias de ruptura e superação, que se recapitula por exemplo em aulas de história da arte e de teoria da arte, é que essa foi uma referência fundamental para a filosofia da arte de autores tão diferentes entre si como G.W.F. Hegel, Theodor Adorno ou Martin Heidegger. ${ }^{8}$ Quer se trate de a continuar, de a contestar, ou de explicitar as suas relações com a filosofia, a referência está lá. Está lá quando Adorno lamenta a substituição da arte e do espírito pela indústria da cultura - quando anuncia que não nos livraremos das garras da razão instrumental ou da arte de massas prototipicamente americana. ${ }^{9}$ Está lá quando Heidegger, na Origem da Obra de Arte, lamenta o esquecimento da abertura ao ser que alguma arte do passado representou e usa, como exemplos dessa arte que abre um mundo, um templo grego ou (aquilo que vê como) os sapatos de uma camponesa num quadro de Van Gogh. ${ }^{\circ}$ Está lá naturalmente quando Hegel fala do fim da arte como um passo da ascensão histórica do Espírito ao reconhecimento de si próprio, sendo a arte de outros tempos e outros lugares superada pela arte do seu próprio tempo e contexto, sendo a arte sempre para ser superada pela religião e pela própria filosofia."

Qualquer forma de olhar para o passado quando se fala de arte, qualquer forma de escolher exemplos em história da arte, pratica uma conceção determinada da história e do histórico' ${ }^{2}$ assim como, naturalmente, uma conceção daquilo que arte é. 0 pensamento de Benjamin sobre a história e o histórico distingue-se claramente do pensamento sobre história e sobre arte de qualquer um dos três autores que acabo de mencionar e que são, todos eles, marcos importantes na conceção do tempo e da história na filosofia contemporânea e na filosofia da arte. Para Benjamin tratar-se-á de não conceber a história, ou a história da arte, de forma sucessiva, linear, cumulativa, como uma lista de acontecimentos (ou uma lista de obras, no caso da história da arte). ${ }^{13}$ Tratar-se-á de, ao pensar sobre história e ao pensar sobre arte, evitar a teleologia hegeliana ou marxista (que é uma forma de pensar sobre o fim do mundo como sendo uma finalidade, uma direção imanente do curso das coisas), e também a história positivista (a história positivista, que se entende a si própria como totalmente científica, objetiva e neutra, é um objeto central da crítica filosófica da Escola de Frankfurt, que patrocinava Benjamin). Tratar-se-á também, por outro lado, de evitar a ontologização da historicidade, a escuta expectante da chamada do ser a partir do futuro e do destino que se encontra em Heidegger, e que Benjamin caricatura como uma fuga para as profundidades de um reino das ideias (Heidegger era alguém contra cujo pensamento 
Benjamin reagia visceralmente). Como veremos, parte da razão para esta reação é o facto de Benjamin não deixar de se considerar um materialista, mesmo se a sua filiação no marxismo da Escola de Frankfurt foi tudo menos ortodoxa. É de um ponto de vista materialista que Benjamin desenvolve uma visão da história e do histórico. Não se trata no entanto de uma visão materialista da história concentrada na história económica e política, como é o caso do pensamento marxista em geral. Por isso Benjamin encontrará na história um lugar para a arte (e para o pensamento) de uma forma que não coincide com a de outras abordagens materialistas.

Em concreto, do ponto de vista desenvolvido por Benjamin (ou a partir de Benjamin) impõe-se a ideia de que uma história cronológica da arte não tem por si própria muito interesse para um artista ou para quem se interessa por arte. ${ }^{14} \mathrm{~A}$ história cronológica é a história daquilo que não é vivo - e aquilo que é vivo, o que está vivo, é o que interessa Benjamin. A sua atenção ao Jetztzeit (tempo-agora) e ao tempo como atualização é uma marca disso mesmo. Esse interesse assumirá a forma de uma crítica ao tempo chamado vulgar, o tempo concebido como estrutura vazia em que sucedem e acumulam momentos presentes, e conduzi-lo-á a ver na arte uma forma de salvação, de culminação do tempo, de iluminação profana. Será que o que Benjamin faz é uma epistemologia da história? Uma ontologia ou metafísica do tempo? Qual é exatamente a consequência das teses sobre a história e o histórico numa visão do que é a arte? Estas questões interessam Eli Friedlander na leitura que faz de Benjamin. ${ }^{15}$ As respostas permitir-nos-ão explicitar o que queremos dizer quando falamos de 'o que a arte tem sido'. No centro estará um exemplo: o Livro das Passagens. ${ }^{16}$

O Livro das Passagens é um fresco heteróclito da 'Paris-capital do século XIX', das suas figuras e formas de vida, que toma como pretexto e título um traço da arquitetura então moderna, as galerias cobertas de vidro unindo ruas num espaço coberto, as passagens. 0 texto de Benjamin não parece filosofia, nem parece ser diretamente sobre história, sobre tempo ou até mesmo sobre arte. Benjamin pratica na sua escrita uma recolha do comum da vida humana e que agora pode mesmo ser entendido como o mais banal da história material. No Livro das Passagens o comum da Paris do século XIX são figuras (o flâneur, o dandy, a prostituta, o jogador, o poeta, o fotógrafo), objetos, lugares e invenções (lojas que virão a ser os grandes armazéns, boulevards, panoramas, moda, bonecas, autómatos, caminhos de ferro, a iluminação de rua). Como é que Benjamin chegou até aqui, como é que chegou a escrever algo como o Livro das Passagens, em torno destes aspetos e detalhes do comum material mais banal? A construção e a montagem são as suas formas de fazer texto e a aproximação destas práticas com o surrealismo foi amplamente sublinhada. Mas como é que Benjamin chegou aqui se começou por se interessar por Kant e pelo conceito de experiência em Kant? Não parece haver relação alguma. Há no entanto uma relação e a relação é precisamente o interesse pela experiência. Kant concebeu a experiência humana de forma percetual e individual, em termos de sensibilidade e entendimento, 
recetividade e conceptualização, e esqueceu a historicidade desta. Mas a experiência humana tem lugar historicamente e é experiência de algo que é em si mesmo histórico. É isso que Benjamin procura recapturar para uma conceção de experiência no Livro das Passagens.

\section{0 que é experienciar historicamente aquilo que é histórico?}

Nas artes e também na filosofia a discussão sobre a história e o histórico aparece quase sempre sob as vestes de uma discussão sobre modernidade, por exemplo (de uma forma marcada por Benjamin) em torno da conceção de moderno em Baudelaire. ${ }^{17}$ A discussão sobre a modernidade, o moderno e o novo é de resto uma razão importante por que a estética tem um lugar tão especial na filosofia contemporânea. Falando de modernidade, do que é moderno ou de modernismo procura-se compreender o que é o vir a ser que acontece na história, o que é o 'ser algo de novo'. Esta é uma questão que interessa naturalmente ao trabalho em artes. Como se captura o que é novo naquilo que passa e que continuamente deixa de ser? ${ }^{18} \mathrm{O}$ que é isso que é capturado? Na sua visão filosófica do comum e do histórico Benjamin dá um papel de relevo a Baudelaire e retoma o tema baudelairiano do 'pintor da vida moderna'. O Pintor da Vida Moderna é uma coleção de ensaios de Baudelaire, elaborados em torno do pintor e desenhador Constantin Guys, que foi publicada em três partes no Le Figaro em 1863 e em L’Art Romantique em 1869. Baudelaire é por sua vez uma omnipresente personagem no Livro das Passagens de Benjamin e na verdade objeto de escritos mais estruturados e mesmo do que teria sido um livro (de Benjamin sobre Baudelaire, Charles Baudelaire: Um poeta na era do capitalismo avançado ${ }^{19}$ ). Naturalmente Friedlander pergunta porquê. Do pintor da vida moderna diz Baudelaire: ele vai, corre, procura. E pergunta: o que procura ele? Responde a si próprio: ele procura o moderno no histórico, o eterno no transitório. 0 que é esse moderno-eterno que se pode encontrar no histórico? Como pode esse moderno-eterno ir sendo sempre diferente e novo? Como pode desaparecer tão imediatamente, sendo substituído por um novo 'novo'?

Olhemos pela mão de Friedlander para a forma como o próprio Benjamin pensa sobre estas questões, ou mais exactamente para o que Benjamin faz no Livro das Passagens. $\mathrm{O}$ que aparece a Benjamin é a contingência, a materialidade concreta e o detalhe. Os conceitos de coleção e de arquivo com que ele próprio caracteriza a tarefa do historiador sublinham isto mesmo. 0 próprio Benjamin escreve fazendo uma coleção, uma justaposição, de materiais textuais. Esta forma de escrever é por si um antídoto contra a ideia filosófica de sistema. A ideia de sistema é uma ideia com pergaminhos na filosofia e utilizada ela própria para sustentar concepções daquilo que é essencial na história. ${ }^{20}$ É no entanto preciso ir mais longe na compreensão do que está em jogo na escrita de Benjamin, para além do contraste imediato com a ideia de sistema. Friedlander sugere que a secção “O colecionador”, a secção H do Livro das Passagens, nos permite entender a forma como Benjamin viu o seu próprio método 
nesse livro (a secção N sobre epistemologia e progresso e método, aquela a que mais frequentemente se faz apelo para compreender a conceção de história de Benjamin, é também fundamental). Mas Friedlander sugere que primeiro que tudo há que olhar para a forma da escrita de Benjamin. Que escrita é esta? Coleciona-se detalhes sobre a história material e esses detalhes vêm na forma de materiais escritos. Mesmo que pareça demasiado óbvio dizê-lo, os materiais de Benjamin são materiais escritos, isto é, não são nem coisas, nem a experiência ela própria de deambular pela Paris do século XIX, a experiência de estar lá, circulando pelas passagens. Ora de materiais escritos faz-se citações; Benjamin é um trabalhador de citações. Benjamin não esteve lá. O trabalho que faz é um trabalho de coleção e colagem de materiais que são citações e que o próprio Benjamin distingue cuidadosamente dos seus próprios comentários. Mesmo tendo trabalhado muitos anos nos materiais, ele quis deixar as citações como citações nas secções do Livro das Passagens, isto é, não quis incorporá-las nas suas próprias palavras (a secção J, sobre Baudelaire, origem do que teria sido o livro Charles Baudelaire - Um poeta lírico no tempo do capitalismo avançado, é uma exceção). Fizera já algo de semelhante no seu escrito A Origem do Drama Trágico Alemão, obra que que descrevera ao amigo Gershom Scholem como 'um mosaico bastante insano.

Os materiais de Benjamin são portanto materiais citados. Ora, como Friedlander nota, uma citação é linguagem retirada do contexto, retirada do contexto de enunciação em que acontecera, tivera lugar. 0 resultado é que citar tem um efeito disruptivo quanto à perceção de importância e de irrelevância que rodeia sempre, contextualiza sempre, o uso de linguagem em ato e que sustenta o nosso entendimento comum e partilhado do mundo quando falamos. Aspetos da significação que poderão não ter sido os originalmente intencionados emergem desta forma. Mais: o método de citação produz um efeito de nivelamento entre o maximamente importante e o trivial, e, como sublinha Friedlander, Benjamin não quer alterar estas condições através de uma intervenção de autor. Mas então, interroga-se Friedlander, como poderemos evitar ver a escrita de Benjamin como um deambular rapsódico e errático por entre materiais banais? Talvez encontremos nestes fragmentos sobre a Paris do século XIX o charme e a estranheza dos objetos antigos e ultrapassados, como os objetos que encontramos numa loja de curiosidades, mas não mais do que isso. Ler Benjamin sobre a Paris do século XIX será semelhante a, por exemplo, visitarmos hoje a casa de Goethe em Frankfurt ou a casa de Mozart em Viena. A estranheza, o charme estão lá mas não está lá a casa de Goethe para Goethe ou a casa de Mozart para Mozart, quando as habitavam. Permanece o que permanece mas o natural âmbito funcional da vida e da experiência, que dá sentido aos objetos e ao entorno, desapareceu, não está lá. Podemos mesmo perguntar para que serve conservar - para que serve manter as coisas assim. E por que pensou Benjamin que a história deveria ser feita de forma (pelo menos aparentemente) análoga? 


\section{Fazer história ou algo de completamente diverso?}

Se o resultado destas reuniões e ajuntamentos de materiais vai ser algo de diferente de um gabinete de curiosidades ou de uma loja de bricabraque, se é verdade que Benjamin tem em mente, com aquilo que faz, com o seu método, conseguir medir-se com um Hegel ou um Marx, ou um Heidegger, no pensamento da história e do histórico, quer dizer, medir-se com as visões dialéticas e totalizadoras da história, mas também com um misticismo da historicidade como doação do ser a partir do futuro, como é que ele pensa conseguir isso? É esta pergunta de Friedlander. E como é que, por exemplo, algo de semelhante à crítica social e política que a orientação marxista subjacente de Benjamin deveria supor, ou que, pelo menos, os seus patrocinadores da Escola de Frankfurt esperam dele, poderá alguma vez sair de um mosaico tal de citações díspares, arbitrárias e ad hoc? O colecionador não chega nunca a criticar, não chega nunca a ser político. Friedlander recorda-nos que Adorno se queixa disso mesmo relativamente a Benjamin. Para Adorno apenas a teoria (social) pode ser o suporte da crítica social. Para a Escola de Frankfurt o hegelianismo e o marxismo têm (ainda hoje) esse papel - essa é outra forma de conceber o que pode salvar-nos, bastante diferente da de Benjamin. $O$ receio de Adorno ao ler os materiais que o próprio Benjamin lhe envia, os fragmentos do Livro das Passagens, é que uma tal imersão em material aparentemente heteróclito e trivial não produza finalmente nada mais do que história positivista e que as questões políticas relevantes do materialismo marxista, as questões da crítica social e da reivindicação, se tornem pura e simplesmente invisíveis.

Será Benjamin um historiador? Benjamin não é um historiador: Benjamin quis sim ser um crítico. 'Crítica' não significa no entanto para Benjamin a crítica social económica e política marxista. Para fazer crítica temos de falar do passado e por isso o crítico tem antes de mais de compreender as nossas relações com o passado. É neste ponto que aparece, talvez inesperadamente, a inspiração teológica do trabalho de Benjamin (algo que assustou, ou mesmo repeliu, pessoas próximas de Benjamin, como por exemplo Bertolt Brecht). A forma textual que Benjamin toma como modelo ao construir o seu próprio texto é o comentário. Pense-se no comentário das escrituras, num contexto religioso e teológico. Sabemos bem que o objeto de comentário é, precisamente, não criticável: o comentário das escrituras não é uma crítica das escrituras. Na verdade o comentário é, pelo menos à primeira vista, o próprio oposto da crítica. A ambição de Benjamin é no entanto capturar na estrutura do comentário a própria construção da história. Ele pensa que não pode haver crítica sem envolvimento no comentário. É a partir destes princípios e com essas armas que Benjamin quer medir-se com os pensadores da história e do histórico que referi atrás.

Consideremos então mais de perto a inspiração teológica, ou 'mística', de Benjamin, fundamental para a ideia de arte como salvação. Benjamin quer transpor para a história uma forma de ver que normalmente pensamos como teológica. O comentário 
é uma forma de tomar parte na realidade 'mais alta' - para isso é preciso, naturalmente, acreditar no Juízo Final. Mas ninguém aqui é crente, diz-lhe Adorno. Nem precisa de ser, responde Benjamin. 0 que está em causa é perceber que isto que estamos a fazer (este pensamento sobre o tempo, sobre a história e o histórico) não é a história do historiador, não é a história concebida como ciência e que se quer ciência. É no entanto precisamente desse pensamento que precisamos para compreender a nossa própria experiência histórica daquilo que é histórico e a forma como ela se dá - e isto é filosofia, podemos dizer.

Os conceitos de rememoração (Eingedenken) e realização, cruciais em Benjamin e cruciais para percebermos a ideia de arte como salvação, entram aqui. Vou explicá-los, mas antes queria fazer uma pequena nota histórico-filosófica. Na verdade (o reparo é de Frielander) a compreensão materialista do mundo de Benjamin é talvez mais influenciada por Goethe do que pelo marxismo. ${ }^{21}$ Com a sua forma de trabalhar, Benjamin pretende contrastar a concretude de uma apresentação, como a apresentação que o Livro das Passagens constitui, com a abstracção do conhecimento, por exemplo o conhecimento histórico, a história escrita pelo historiador. O Livro das Passagens é, diz Friedlander, uma miniatura filosófica que é ela própria uma apresentação. Segundo Friedlander a ideia de visibilidade ou intuibilidade mais intensa da história que Benjamin propõe remete na verdade para Goethe. Benjamin pretendeu transpor o conceito goethiano de Urphänomenon, fenómeno originário, do contexto da natureza para o contexto da história. Segundo Goethe, o Urphänomenon ou fenómeno originário revela a essência e unidade da natureza, mas não é apreensível directamente na nossa experiência comum da natureza. Isto não quer dizer, no entanto, que seja extra-natural. Procurar o Urphänomenon ou tornar presente a unidade de uma origem não é procurar por trás dos fenómenos ou procurar um acontecimento primeiro. Os factos são já teoria, pensava Goethe. Com o conceito de Urphänomenon Goethe rompe com o naturalismo vulgar no estudo da natureza e Benjamin pretende fazer o mesmo quanto a história. A ruptura pretendida com o que chama naturalismo histórico vulgar não pretende deitar fora o naturalismo; ela é feita em prol de uma forma mais elevada de naturalismo.

Consideremos então finalmente os conceitos de realização e de Eingedenken, rememoração. A rememoração é a chave benjaminiana para a experiência histórica do histórico. Como vimos, o trabalho de Benjamin opera com citações. Ora, algo análogo se passa com a nossa experiência histórica do histórico. Temos fragmentos do passado; é isso e apenas isso que está materialmente connosco agora. Há apenas isso, não há mais nada: só temos ruínas, despojos, fragmentos. Isso é assim não apenas no caso da vida material, dos objetos que nos rodeiam, mas também no caso de textos - pensemos na llíada, na Divina Comédia, ou em As Flores do Mal ou na Origem da Tragédia, ou no O Rei Lear, ou no próprio Livro das Passagens de Benjamin. Não estão aí as pessoas que escreveram esses textos, como não estão aí as pessoas 
que pintaram aqueles quadros que nos capturam especialmente na história da pintura, ou as pessoas que compuseram sinfonias que ouvimos ou que construíram os templos que vemos hoje à nossa frente em Atenas. Estão todos mortos. ${ }^{22}$ Os autores não acompanham as coisas materiais que fizeram e que nos chegam. Essas coisas que nos chegam são tudo o que temos. Ora essas coisas podem segundo Benjamin ser utilizadas ou numa tentativa de reconstruir o passado ou como fragmentos do futuro. A unidade que é construída quando temos encontros com fragmentos, ruínas ou despojos do passado é um retomar histórico da história (por exemplo pelo próprio Benjamin no Livro das Passagens, ou fazendo história da arte). Não é o próprio passado. ${ }^{23}$ Como sublinha Friedlander, o retomar histórico da história não pode ser identificado com o espaço dos factos ou com a unidade da experiência do tempo. Não é, nem poderia ser, aquilo que já foi, aquilo que já aconteceu. Replicar o passado é simplesmente impossível. 0 passado não é; ${ }^{24}$ não traremos nunca de volta aquilo que já foi e deixou de ser. Tudo o que podemos fazer é realizar o passado rememorando. Como? O retomar histórico da história pelo artista - ou pelo filósofo, como é o caso de Benjamin - não é o escrever história do historiador. 0 artista está a construir. Construir a história é uma forma de realizar o passado, não de o reconstituir. Ora construir algo dessa forma é segundo Benjamin ao mesmo tempo destruir e redimir. É, também, para Benjamin, tomar parte na realidade mais alta, o arquétipo ou ideal, do qual o texto quer ser comentário. A ideia de realização do passado deve ser entendida ontologicamente e não apenas epistemologicamente: o que é visado não é mero conhecimento mas uma significação mais alta. ${ }^{25}$

Tudo isto leva Benjamin a pensar que, para além da contingência, da materialidade concreta e do detalhe das recolhas de materiais comuns, pode haver uma unidade, a unidade de uma imagem - é a esta unidade que Benjamin chama imagem dialética. Este é um dos mais conhecidos conceitos de Benjamin. 'Imagem' não significa agora imagem como veículo material concreto tecnicamente reprodutível, como quando falamos por exemplo de fotografia. Não significa fotografar esta Paris do Livro das Passagens (embora isso tenha sido feito, e as fotografias sejam certamente objetos que desde sempre muito interessaram Benjamin). Imagem dialética significa a vinculação de um agora com um outrora, ${ }^{26}$ com o que já foi. Aquilo que Benjamin procura é a intensificação da intuibilidade da história (esta expressão é central para Friedlander) numa imagem dialética. É isso que ele próprio procura fazer no Livro das Passagens através de uma coleção de materiais (os materiais da Paris do século XIX, desde a nova arquitetura das passagens até às exposições mundiais, até à vida e obra de Baudelaire), que são, naturalmente, materiais escritos, colecionados, citados, comentados.

Ao dizer tudo isto o materialista histórico que é Benjamin está a falar de escrita de um ponto de vista materialista. Ou seja, está a falar da linguagem e da forma como a escrita e a linguagem permeiam a nossa experiência histórica da história. Quando 
o materialista histórico que é Benjamin pensa que para além da contingência pode haver uma unidade, essa unidade não é então a unidade de um sentido teleológico da história como em Hegel ou Marx e que de alguma forma nos permitiria falar de uma história universal, ou de um sentido da história - e, assim, de um fim (como finalidade) do mundo nesse sentido. E por isso mesmo qualquer salvação concebida nesse quadro deixa de fazer sentido. A unidade da imagem dialética que Benjamin tem em mente só pode ser conseguida na linguagem, e, logo, nas artes ou no pensamento apenas dessa forma pode ser proporcionada uma visibilidade mais intensa da história. Só essa pode ser a salvação.

Como poderemos compreender tal intensificação da visibilidade da história? Um ponto decisivo na visão que Benjamin tem do histórico é que a realização do tempo não se faz sozinha, não se faz por si. Segundo a visão benjaminiana do tempo não há uma sucessão cumulativa de presentes, não há uma marcha dialética como em Hegel ou Marx, que por necessidade imanente conduz a um telos, a uma finalidade, seja o Espírito Absoluto, ou uma sociedade comunista futura. Não há tão pouco o Ser heideggeriano determinando a nossa época 'a partir de cima', doando-se, originando a história a partir do futuro, como uma doação misteriosa supra-humana, que podemos apenas aguardar, passivamente, como um destino. A realização ou atualização do tempo precisa de nós, 'aqueles que estamos vivos agora'. Dizer que a realização ou atualização não acontece por si como em Hegel ou Marx - a partir de quem se pôde falar de uma 'marcha da história' e, no caso de Marx, em direção à revolução - é dizer que a realização precisa do presente, de um ponto de vista. Esse ponto de vista é o nosso, não é o ponto de vista da história, ou o ponto de vista do Espírito Absoluto ou do socialismo como em Hegel ou Marx, ou o ponto de vista do Ser como em Heidegger. $\mathrm{O}$ que acontece então quando por exemplo 'pomos' alguma coisa na história da arte (Homero, Safo, Giotto, Dante, Shakespeare, Camões, Picasso, Stravinsky, Eliot, Debussy, Schönberg, Pessoa ou Beckett, ou Pedro Cabrita Reis ou Jakob Lena Knebl, para retomar os meus exemplos iniciais)? O que acontece é que, ao fazê-lo, nós partilhamos a nossa vida com o passado. Essa partilha é sempre com um passado específico, idiossincrático, da mesma forma que a vida de uma pessoa é idiossincrática. Poderíamos dizer que determinados factos do passado nos acontecem a nós, agora, aqui. Dois períodos ou momentos da história relacionam-se, encontram-se. Dois momentos relacionam-se também quando por exemplo alguém traduz um texto, por exemplo um grande texto de literatura. A tarefa do tradutor é por isso um outro modelo benjaminiano, uma figura-chave, além do colecionador, para a forma como a realização da significação na história acontece. 0 próprio Benjamin trabalhou muito na tradução de Proust, embora as suas traduções não tenham tido o destino esperado. Afirmava que Proust o tinha 'envenenado' de forma definitiva, que nunca o tinha abandonado. Benjamin é tradutor de Proust e Proust representa o rememorar que transforma: importante quanto à tradução é que ela não é nunca perfeita, não é 
nunca total.É assim também na imagem dialética, na construção progressiva da realidade para alcançar um nível mais alto de atualidade. É apenas assim que aparece a frágil força messiânica da tarefa de escrever, ou de fazer arte. É desta forma que está o colecionador, o tradutor, o crítico - o artista, ou o filósofo (do tempo e da história) que é Benjamin, com o seu texto.

Perguntei atrás se aquilo que Benjamin faz é uma epistemologia da história ou uma metafísica do tempo. Essas não são no entanto as boas perguntas. ${ }^{27} \mathrm{~A}$ posição de Benjamin sobre a história e o histórico é uma posição sobre linguagem e sobre escrita - sobre o facto de ser com linguagem e com escrita que acontece e se faz a nossa relação com o tempo e em particular com o passado. Por ter este interesse pela linguagem e pela escrita no seu centro, o materialismo histórico de Benjamin não poderia deixar de ser bastante diferente da visão de um Marx. O 'motor da história' para Marx são as relações de produção. As questões de Benjamin são-lhe invisíveis. O materialismo histórico de Benjamin fá-lo ir atrás de coisas diferentes: permite-lhe afirmar por exemplo que a arte é capaz de iluminação profana, o que não parece de todo marxiano, e que de resto, na intenção do próprio Benjamin, supera o naturalismo vulgar que podemos considerar associado ao marxismo.

É importante notar que, se na conceção puramente 'materialista-concretista' de história de Benjamin está em causa resistir à integração numa totalidade, uma nota presente na ideia filosófica de sistema, presente no pensamento de um Hegel ou de um Marx, não se trata necessariamente de resistir à ideia de revolução. Poderíamos pensar nos seus escritos sobre arte e técnica, em que abordou as questões da arte de massas $^{28}$ e da reprodutibilidade técnica de uma forma que é ainda hoje importante para nós. 0 pensamento de Benjamin está aberto à revolução nomeadamente através de uma compreensão filosófica da técnica na relação desta com as artes - isto seria muito estranho por exemplo a alguém como Heidegger. Noutras palavras, não é apenas quanto a conceções de história e histórico que os dois divergem profundamente mas também quanto a questões como a técnica e a revolução. Mas não irei por aí.

Friedlander pretende em geral enfatizar que, não obstante o seu (assim chamado) messianismo, Benjamin não deixa de ser um materialista e um naturalista, um materialista que procura um materialismo para além de Marx, para além da Escola de Frankfurt, e um naturalista inspirado por Goethe, levando assim a sua conceção da experiência para além da de um Kant. É o próprio Friedlander quem pergunta, no entanto, por que havemos de tomar a proposta de Benjamin sobre a história e o histórico como sendo uma forma de naturalismo, um 'naturalismo mais elevado' e não simplesmente, por exemplo, uma espécie de surrealismo. 0 próprio Benjamin admite que ao falar da nossa experiência histórica do histórico fala de uma ilusão. É uma ilusão real, uma ilusão existente em configurações de vida real e atual, embora com toda a qualidade de sonho e utopia do passado, mas é uma ilusão. A questão de Friedlander é muito pertinente, no entanto não tentarei responder-lhe aqui. 


\section{Arte e tempo: Benjamin, o anti-Heidegger}

Quero terminar fazendo notar algumas características mais do pensamento de Benjamin sobre o tempo que me parecem ser uma ajuda inabdicável quando somos hoje confrontados com o facto de necessitarmos de conceções da história e do histórico para falar filosoficamente sobre arte. Que necessitamos de facto de conceções da história e do histórico para falar filosoficamente sobre arte, e que deveremos falar sobre a história e o histórico sem apelar à ideia de um 'fim do mundo' como direção dos acontecimentos (como Hegel ou Marx pensavam poder fazer), é um ponto de Heidegger. É essa uma das razões por que Heidegger é tão frequentemente convocado neste contexto. Ora, penso que é iluminador ver Benjamin como um anti-Heidegger. Procurarei dizer brevemente porquê.

O pensamento heideggeriano acerca de historicidade, esboçado na segunda parte de Ser e Tempo (Heidegger 2012) e continuado na obra posterior, e que inclui uma extensão à arte, tem no centro o Ser e a ideia de historicidade como doação pelo ser e expectância pelos humanos. No entanto, a estas ideias mais abstratas, metafísicas ou 'anti-metafísicas', liga-se uma ideia bem mais mundana, sem a qual não leremos bem Heidegger, que é a ideia de uma degenerescência da cultura no tempo que vivemos (que ele expressa por exemplo com a famosa afirmação "Só um deus poderia ainda salvar-nos” na entrevista que deu ao Der Spiegel em 1966, Heidegger 1989). Esta ideia de degenerescência e 'fim do mundo', caracterizando o (nosso) tempo, um tempo em que a metafísica se apresenta como ciência e técnica e dominação da natureza, é acompanhada, em Heidegger, por uma ideia de salvação, uma ideia que é oficialmente despida de qualquer resquício teológico. Essa ideia de salvação é articulada por Heidegger em torno de convicções como por exemplo o destino de um povo e o privilégio de uma particular língua (grego ou alemão) na abertura do pensamento ao Ser. ${ }^{29} \mathrm{O}$ célebre “Discurso do reitorado" (Heidegger 2007), pronunciado quando Heidegger se torna o primeiro reitor nacional-socialista da Universidade de Freiburg, é expressão disso mesmo e retoma, em torno da missão espiritual e destino histórico da universidade alemã em 1933, temas da sua filosofia anterior, nomeadamente de Ser e Tempo. Em tudo o que vimos atrás Benjamin está a reagir a visões do fim do mundo e da salvação como as de Heidegger sem no entanto o fazer da forma marxista clássica praticada por exemplo pela Escola de Frankfurt (totalmente política e económica, totalmente 'imanente' nesse sentido). No que vimos atrás, Benjamin está a repudiar ideias de 'privilégio' e 'destino espiritual' que encontramos na salvação formulada à maneira de Heidegger e que levaram este, de uma forma que não foi de todo contingente, a aderir ao nacional-socialismo e portanto a uma esperança política e histórica de salvação. A esperança política e histórica de salvação de Heidegger está ligada ao Ocidente. Ora, não existe, desde logo, em Benjamin, ao contrário do que acontece em Heidegger (ou Hegel, ou Adorno) um prendimento necessário ao Ocidente: quando Benjamin fala de configurações de vida real e atual, de imagem dialética ou de inten- 
sificação da intuibilidade da história, podemos tomá-lo como falando de configurações da vida humana qualquer. Não se encontra tão-pouco em Benjamin o perfume de desgosto desdenhoso pelo mundo presente que podemos encontrar em Heidegger. Além disso, a posição de Benjamin sobre a nossa relação epistemológica e ontológica com a temporalidade da nossa existência dá um papel filosófico e epistemológico à arte bastante mais específico do que o apelo de Heidegger (por exemplo em A Origem da Obra de Arte) à 'Terra' e às 'coisas'. Heidegger toma como exemplo os sapatos de Van Gogh e o templo grego, e afirma de forma vaga que "a arte e só a arte será a salvação do ocidente" (a ser lido em paralelo com "só um deus poderá ainda salvar-nos”: o responsável em qualquer dos casos seria o Ser). Na escolha dos exemplos de Heidegger sobressaem o classicismo e a ruralidade, o que certamente convém ao nacional-socialismo que então professa. Os objetos materiais banais recolhidos e colecionados (em linguagem) no Livro das Passagens, e a exploração de artes técnicas como a fotografia e o cinema (em "A obra de arte na época da sua possibilidade de reprodução técnica”) são a forma de Benjamin resistir àquilo a que chama 'a fuga de Heidegger para as profundezas’ bem como à sua interpretação político-mística de tais profundezas. É muito importante notar que na visão da história e do histórico que encontramos em Benjamin não há nada de superior a nós, humanos, que estamos aqui agora, vivos. Não há 'o Ser' ou 'a marcha da história'. Não há sociedades em progresso ou em decadência: a conhecida crítica de Benjamin à ideia positivista de progresso é acompanhada por uma crítica à ideia de decadência. ${ }^{30}$ Ao contrário do que Heidegger pensa não há tão-pouco línguas melhores ou piores "para exprimir o Ser'. Poderíamos dizer que ao contrário do que pretendeu Heidegger, a filosofia, por exemplo, não se faz apenas, ou sobretudo, em grego ou em alemão. ${ }^{31}$ Faz-se na língua em que se fizer. Haverá sempre uma língua, havendo humanos - esse é aliás, hoje, o início da filosofia para os filósofos do comum (podemos pensar em Ludwig Wittgenstein, J. L. Austin ou Stanley Cavell). Mas essa língua é uma língua qualquer. Abre-se aqui de resto uma relação possível de Benjamin com outras tradições filosóficas contemporâneas, por exemplo a tradição de língua inglesa, que Heidegger não vê sequer como filosofia. Podemos pensar em Cavell e na sua releitura da filosofia do comum. Encontramos aqui mais um contraste com Heidegger: ao contrário de Heidegger, a filosofia do comum não apela à ocupação ou habitação de um lugar (que faz esse apelo por exemplo em “Construir, habitar, pensar”), mas sim a partir, abandonar, tornar-se, ideias que por exemplo Cavell explora em The Senses of Walden ${ }^{32}$ a partir de Emerson e Nietzsche e, poderíamos dizer, contra Heidegger. Como diz Cavell, ${ }^{33}$ a filosofia está em sua casa simultaneamente em toda a parte e em parte nenhuma. Isto mesmo poderíamos dizer de Benjamin, contra Heidegger. 


\section{Linguagem, finalmente.}

Termino com uma observação sobre linguagem. 0 pensamento de Benjamin sobre a história e o histórico explora o que fazemos quando usamos linguagem. Isso faz toda a diferença na forma como em filosofia se trata de estética e arte. Cavell faz notar a certo ponto em "Music discomposed”, um capítulo do seu livro Must We Mean What We Say (Cavell 1969), que a separação entre filosofia e crítica é em última análise artificial e perniciosa. Arthur Danto faz uma afirmação análoga. Ora Benjamin é precisamente um filósofo que é um crítico, um crítico que nos mostra por que a crítica não passa sem pensamento sobre a natureza da ação linguística, simbólica, literária. É isso precisamente que Benjamin faz. Não podemos passar por cima da linguagem e do que esta faz quando exploramos o que queremos dizer com história e com história da arte, ou quando dizemos que algo é arte "quando esse algo é posicionado intencionalmente por um artista sobre o pano de fundo da história da arte”, como diz Levinson. Os artistas estão na posição do colecionador e do tradutor de Benjamin lidando com os seus materiais. Os materiais do artista não são materiais nus, puras coisas à minha frente. 0 artista encontra materiais. Os materiais são deste mundo. 0 artista utiliza-os, transpõe-nos, retira-os de contextos, faz com que falem de uma outra maneira. Trying to make sense, como diz Cavell. Podemos pensar num escritor, num arquiteto, num artista plástico, ou também num músico (que é o exemplo de Cavell em "Music discomposed”). Podemos ler Benjamin como dizendo que tomar historicamente materiais que são eles próprios históricos e fazer arte é precisamente visar um nível mais alto de atualidade. Esta é uma tese sobre tempo e uma tese que tem um impacto direto na conceção daquilo que a arte é e a arte faz. Isso significa naturalmente que, ao definirmos histórica e intencionalmente a arte como faz Levinson, se abre um abismo: o abismo da temporalidade da nossa existência. É aí mesmo que Benjamin coloca a linguagem. Podemos no entanto navegar sobriamente sobre esse abismo - é o que faz Levinson com a sua definição intencional-histórica de arte. Se as conceções de história e de histórico de Heidegger e de Benjamin são realmente incompatíveis, o mesmo não acontece com Benjamin e um filósofo analítico da arte como Levinson. Na verdade Benjamin pode até ajudar-nos a resolver um problema com que Levinson nos deixa, com a sua definição anti-essencialista de arte. É por vezes argumentado que na definição de arte que Levinson nos dá fica em causa uma Ur-arte, uma arte inicial, que não poderia ser vista como arte porque não temos nenhum pano de fundo de história da arte contra o qual possamos vê-la como arte. Para responder a Levinson Benjamin diria que temos aí, já, algo de fundamental na nossa forma de ser no mundo: a linguagem e a história. A origem da arte é precisamente essa. Retomando a ideia de Goethe, lida por Benjamin, 'origem' não tem de ser uma datação temporal. ${ }^{34}$ Isto significa que não precisamos de procurar a origem da arte num tempo remoto da evolução da espécie humana: na origem da arte encontram-se a linguagem e a história, agora, aqui, para nós. Esta é uma razão por que os humanos se envolvem nessas atividades a que chamamos arte. 


\section{Notas}

* Sofia Miguens é Professora Catedrática do Departamento de Filosofia da FLUP e Diretora do Instituto de Filosofia da mesma Universidade. Livros recentes: Uma Leitura da Filosofia Contemporânea - Figuras e movimentos (Edições 70, 2019), The Logical Alien (Harvard University Press, 2020). Artigos recentes: "Temptation and therapy - Wittgensteinian responses to other minds skepticism", Wittgenstein Studien, 2019; "The human face of realism - Putnam and Diamond on the ethical "gulfs between us", The Monist, 2020; "What is the difference between Hamlet and me? Fiction, metaphysics and the nature of our moral thinking”, in Abstract Objects, 2020; “The quest for a voice - The importance of Cavell's notion of claim for ethics and aesthetics”, Journal for the History of Analytical Philosophy 202।.

' Agradeço muito ao Pedro Eiras o convite para participar neste ciclo, um convite que satisfez um desejo antigo meu de colaborar com os meus colegas da FLUP que trabalham em literatura e artes. A leitura de libretos anteriores deu-me já de resto, e também isso agradeço, outros pretextos para cruzamentos da literatura e das artes com a filosofia, para além dos explorados neste artigo.

'Esta forma de colocar a questão não é totalmente justa para com Danto. Danto chama 'mundo da arte' (artworld) mais propriamente ao conhecimento que nos permite estar na posição de ver-como arte determinados objectos, situações e acontecimentos (um framing teórico, portanto) do que a pessoas e instituições que sancionam socialmente o que conta como arte. Interessa-me aqui no entanto fazer um contraste.

${ }^{3}$ Óptimos guias em português são Nigel Warburton, O que É a Arte? (2007), Aires Almeida, "Estética e Filosofia da Arte" (2012), e Noel Carroll, Filosofia da Arte (2015). Veja-se ainda a antologia coordenada por Vítor Moura, Arte em Teoria - uma antologia de estética (2009).

${ }^{4}$ O célebre escrito de Adolf Loos Ornamento e Crime (1931) pode ser hoje uma obra difícil de ler pelas ressonâncias de superioridade civilizacional que nela percebemos. É de qualquer forma uma obra incontornável, endereçada contra o Art Nouveau e o detalhe decorativo e que veio a ser importante para um movimento como a Bauhaus.

${ }^{5}$ A realidade é mais complicada: na verdade nós reapoderamo-nos das discussões e desta forma transformamo-las (como atesta uma exposição com algumas semelhanças relativamente àquela que acabo de descrever, intitulada Oh! e comissariada pela artista austríaca Jakob Leena Knebl, em 2017, no mumok, em Viena, e que esteve na origem do meu exemplo).

${ }^{6}$ Como Danto nota em The Artworld, 'revoluções' conceptuais naquilo que pensamos sobre arte provocaram por exemplo migrações de objetos específicos de museus de antropologia para museus de arte contemporânea.

${ }^{7}$ Ver Bernardo Pinto de Almeida, Arte e Infinitude (2018).

${ }^{8}$ Ver Miguens 2019 para visões panorâmicas do pensamento de cada um destes autores, que enquadram as suas posições acerca de arte.

${ }^{9}$ Seria interessante comparar o sentimento de Adorno, de acordo com o qual "uma noite vem da América”, toda a arte degenera em kitsch, ou ainda o seu (muitíssimo controverso) ensaio On Jazz, com a apreciação filosófica da América em Emerson. Emerson foi lido por Nietzsche, sendo ambos, Emerson 
e Nietzsche, influências marcantes, hoje, da forma perfeccionista de pensar sobre estética e ética do filósofo americano Stanley Cavell.

${ }^{10}$ Um Par de Sapatos, Van Gogh, 1886.

"Sem naturalmente esquecer a discussão de Hegel com os românticos seus contemporâneos (veja-se a sua Estética), onde ressaltam importantes diferenças. Mas a discussão de Hegel com os românticos seus contemporâneos é uma discussão entre pares e num contexto comum. Pode-se discutir opções na música alemã, mas Hegel não daria à arte africana ou à arte indiana do seu tempo igual dignidade intelectual ou metafísica. Ver no entanto Danto 2013 sobre como não renegar Hegel não o historicizando e culturalizando de forma excessiva. Segundo Danto o que Hegel está fundamentalmente a dizer é que a arte 'vem a si própria', isto é, ascende ao saber de si própria (ver Danto, After the End of $\operatorname{Art}($ 1997)).

${ }^{12}$ Como afirmei atrás, uso o termo ‘história' para o reportar daquilo que aconteceu e o termo 'histórico' para aquilo que aconteceu e acontece, o dar-se dos acontecimentos.

${ }_{13}$ Podemos encontrar em Aby Warburg (1866-1929) um exemplo da prática da história da arte que Benjamin virá a retratar filosoficamente.

${ }^{14}$ Ver Filomena Molder, Aulas de Estética, disponíveis no Youtube (filmadas por Luís B. Tavares).

${ }^{15}$ Friedlander foi aluno de Cavell em Harvard e é professor em Telavive. Vem de temas wittgensteinianos e escreve sobre Kant e Walter Benjamin. Considerarei aqui sobretudo o seu livro Walter Benjamin - $A$ Philosophical Portrait (2012) e a análise da ideia de uma visibilidade mais intensa da história, tal como esta é apresentada no Livro das Passagens (PassagenWerk).

${ }^{16}$ A tradução e edição portuguesa de João Barrento (As Passagens de Paris, Assírio e Alvim) inclui a introdução à edição alemã de 1982 (de Rolf Tiedemann), que contém uma história detalhada destes escritos que não chegaram a ser publicados, bem como as duas sinopses escritas por Benjamin e primeiros apontamentos e esboços. Tiedemann sugere que com a ajuda das sinopses podemos imaginar em torno dos materiais (ordenados em secções com títulos gerais marcadas como A-Z, a-w), o que teria sido a forma desta obra de Benjamin.

${ }^{17}$ Ver a tradução de Charles Baudelaire (182I-1867) para o português (O Pintor da Vida Moderna) e a introdução de Teresa Cruz. A obra mais conhecida do poeta francês é o livro Les Fleurs du Mal, As Flores do Mal, objecto de atenção intensa por parte de Benjamin.

${ }^{18}$ Pense-se na forma como Michael Fried e Arthur Danto, ambos críticos de arte, além de académicos, caracterizam o trabalho do crítico de arte como como sendo regido pela obsessão What's next? What's the next thing?

${ }^{19}$ Ver a edição de Giorgio Agamben.

${ }^{20}$ A ideia de sistema é uma ideia kantiana e é uma (outra, diferente) ideia hegeliana. Ver Miguens (2019) sobre Kant, Hegel e também sobre Marx, e sobre aquilo que é essencial na história para cada um. Para Hegel há um 'sentido’ na história da humanidade, isto é, uma direcção na sequência de civilizações e impérios e formas culturais. Essa é uma leitura da ideia de 'fim do mundo' como finalidade da história, direcionamento a algo. Esse sentido é o auto-conhecimento do Espírito Absoluto (Espírito Absoluto é o sujeito da filosofia de Hegel, o nome que dá a realidade). Segundo Hegel, o Espírito volta a si próprio progressivamente na história humana após a sua exteriorização ou alienação na natureza. 0 auto- 
-conhecimento do Espírito realiza-se pela história e no fim da história. A arte, a religião e a filosofia são três formas sucessivas deste auto-conhecimento do Espírito. Hegel considera que aquilo que foi ‘novo' ao longo da história é mantido naquilo que é negado (i.e. que deixou de ser). 0 termo que Hegel utiliza aqui é Aufhebung (elevação-superação). A história é assim para Hegel um processo dialético, um processo de superação, com uma direcão e um fim, um processo em que a negação é característica da própria realidade. Marx manterá na sua visão da história elementos da visão dialética de Hegel, adaptando-os ao ponto de vista materialista e considerando o espírito e a história humana não como um sujeito mas como um reflexo da estrutura económica material. As concepções de história dos dois autores e a discussão destas, nomeadamente no pensamento seu contemporâneo, constituem um pano de fundo essencial para compreender o trabalho de Benjamin.

${ }^{21}$ Molder e Friedlander coincidem nesta afirmação.

${ }^{22}$ Não perguntemos agora por autores vivos. Mas se perguntássemos poderíamos iniciar a resposta com os versos de T. S. Eliot: "He who was living is now dead. We who were living are now dying. With a little patience" (The Waste Land, vv. 328-330).

${ }^{23}$ Só assim pode Benjamin escapar de uma acusação que lhe viria quase necessariamente da filosofia analítica: a acusação de estar a apresentar uma injustificada concepção idealista do tempo.

${ }^{24}$ Esta afirmação é naturalmente muito polémica do ponto de vista filosófico e também da física; basta pensarmos na relação entre o chamado eternismo na metafísica do tempo e a física relativista. Do ponto de vista da relatividade, passado, presente e futuro são igualmente reais.

${ }^{25}$ Deixemos de lado o que isto significa para a prática da história por exemplo económica e política ou para as ciências naturais que são sobre o passado (como astronomia, a geologia, ou a paleontologia) e pensemos na nossa própria experiência histórica do histórico e na história da arte. É este o nosso problema, pelo facto de a história da arte ser tantas vezes convocada em definições de arte.

${ }^{26}$ Retomo a expressão de Filomena Molder.

${ }^{27}$ É claro, certamente, que Benjamin pode ser criticado precisamente por aí. Uma crítica do lado heideggeriano seria que Benjamin está no máximo a apresentar uma epistemologia do tempo, não uma ontologia do ser e do tempo.

${ }^{28}$ Ver Noel Carroll (1998), para uma cuidadosa interpretação de Benjamin. Carroll usa Benjamin como exemplo da "celebração filosófica da arte de massas", oposta à "rejeição filosófica da arte de massas".

${ }^{29}$ Ao que se junta ainda (numa expressão ouvida a Filomena Molder) a "germanização à força dos gregos".

${ }^{30} \mathrm{~A}$ apresentação materialista da história é acompanhada por uma crítica imanente ao conceito de progresso, afirma Benjamin em Nil.4, Livro das Passagens.

${ }_{31}$ “Não crer em épocas de decadência. Do mesmo modo (...) toda a cidade para mim é bela; e também não aceito que há um valor maior ou menor das línguas” (Nı, 6, Livro das Passagens)

${ }^{32} \mathrm{O}$ texto foi escrito depois de Cavell ler "Construir, habitar, pensar" de Heidegger.

${ }^{33}$ Citado em Laugier (2013: 28).

${ }^{34}$ É certo que por aí poderíamos chegar também à ideia segundo a qual os artistas são todos contemporâneos (a ideia é trazida à tona por Filomena Molder nas suas aulas de estética online). 


\section{Bibliografia}

Almeida, Aires (2012), “Estética e Filosofia da Arte”, in Filosofia - uma introdução por disciplinas, coord. Pedro Galvão, Lisboa, Edições 70.

Benjamin, Walter (2017), A Modernidade, ed. e trad. João Barrento, Lisboa, Assírio e Alvim.

-- (2017a), "A obra de arte na era da sua possibilidade de reprodução técnica”, in Benjamin 2017.

-- (2019), As Passagens de Paris, ed. e trad. João Barrento, Lisboa, Assírio e Alvim.

Carroll, Noel (2015), Filosofia da Arte, Lisboa, Texto e Grafia.

Cavell, Stanley (1969), Must We Mean What We Say?, Cambridge, Cambridge University Press.

-- (1981), The Senses of Walden, San Francisco, North Point Press.

Danto, Arthur (1964), “The artworld”, The Journal of Philosophy, 61, 19: 571-584.

-- (1997), After the End of Art - Contemporary art and the pale of history, Princeton, Princeton University Press.

Friedlander, Eli (2012), Walter Benjamin - a Philosophical Portrait, Cambridge MA, Harvard University Press.

Heidegger, Martin (1989), “Já só um deus nos pode ainda salvar”, trad. anotada Irene Borges Duarte, Filosofia, III, I/ 2: I09-135 [1966].

-- (2002), "A origem da obra de arte”, in Caminhos de Floresta, coord. e trad. Irene

Borges Duarte, Lisboa, Fundação Calouste Gulbenkian [1935-36].

-- (2007), "A auto-afirmação da universidade alemã - o discurso da Reitoria”, trad.

Daniel Pucciarelli, Revista Terceira Margem, n0 II, 17: 149 - 165 [1933].

-- (2012), Ser e Tempo, ed. bilingue, trad. e org. Fausto Castilho, São Paulo, Vozes [1927]. Levinson, Jerrold (2020), Investigações Estéticas - Ensaios de filosofia da arte, trad. Vítor Guerreiro, Porto, Afrontamento.

Miguens, Sofia (2019), Uma Leitura da Filosofia Contemporânea - Figuras e movimentos, Lisboa, Edições 70.

-- (no prelo), Arte Descomposta - Stanley Cavell, a estética e a filosofia.

Molder, Filomena (2011), O Químico e o Alquimista - Benjamin leitor de Baudelaire, Lisboa, Relógio d’Água.

-- Estética - Aulas (online, YouTube, filmadas por lbtavares).

Moura, Vítor (2009), Arte em Teoria - Uma antologia de estética, Famalicão, Húmus.

Pinto de Almeida, Bernardo (2018), Arte e Infinitude - O contemporânea entre a arkhê e o tecnológico, Lisboa, Relógio de Água.

Warburton, Nigel (2007), O que É a Arte?, trad. Célia Teixeira, Lisboa, Bizâncio. 